\title{
Association of Visceral Adiposity Index Score with the Severity of Coronary Artery Disease in Patients with Ischemic Heart Disease
}

\author{
Chayan Kumar Singha ${ }^{1}$, Eshita Biswas ${ }^{2}$, Amal Kumar Choudhury ${ }^{3}$, Md. Khalequzzaman ${ }^{4}$, Rawshan Arra Khanam ${ }^{5}$, \\ Sanzida Mahmood ${ }^{6}$, Nandita Paul ${ }^{7}$
}

\begin{abstract}
:
Background: Ischemic Heart Disease (IHD) is the leading cause of death throughout the world and obesity especially visceral adiposity (central obesity has significant influence for its development \& progression. Visceral adiposity index (VAI) is a novel sex specific index which had significant correlation with visceral adiposity. Objectives: To evaluate the impact of cut-off points of VAl defining visceral adipose dysfunction (VAD) on the angiographic severity of coronary artery disease in patients of IHD. Methods: A total of 100 patients with IHD were divided into Case (of which 50 patients of IHD with VAD positive) and Control group (of which 50 patients of IHD with VAD negative). Then clinical, biochemical, echocardiographic and coronary artery angiographic indexes (determined by Gensini score) were acquired in relation to VAI. Results: VAD positive group had more significant form of coronary artery disease in term of Gensini score than VAD negative group.The mean level of Visceral Adiposity Index (VAI) was observed 3.1 \pm 0.9
\end{abstract}

and 2.1 \pm 0.6 in significant CAD (Gensini score $\geq 36$ ) and insignificant CAD (Gensini score $<36)$ respectively. The difference of mean VAI between the significant and insignificant CAD groups were statistically significant $(p=<0.001)$. First group (VAD positive) also had more CAD risk factors like hypertension, diabetes mellitus and dyslipidemia which were significantly higher than second group (VAD negative) $(p=0.02,0.002,0.01)$. Univariate and multivariate analysis revealed that out of the 8 variables hypertension, dyslipidemia, diabetes mellitus, waist circumference and visceral adiposity index were found to be the independently significant predictors of severe CAD patients with ORs being 1.61 vs. $1.52,1.97$ vs. 1.36 , 2.19 vs. $1.97,1.94$ vs. 1.61 and 3.89 vs. 3.49 respectively. Thus the VAl was found to be more strong predictor of the severity of CAD. Conclusion: VAl is a simple indicator of visceral adipose mass \& was markedly associated with the severity of coronary artery disease in IHD patients.

Key words: Coronary artery disease, Viscereal, Adiposity.
Introduction:

Obesity, a worldwide epidemic in recent years and around 2.1 billion people-nearly one-third of the world's population are overweight or obese $\&$ it is one of the important modifiable risk factor. ${ }^{1}$ Apart from CVD it also increases type 2 diabetes, Obstructive sleep apnea, certain types of Cancer, Osteoarthritis, Depression, Sexual dysfunction, Alzheimer's. ${ }^{2}$
However, not every obese patient develops cardiovascular diseases. In this regard, visceral adiposity has been found to play a key role in cardio metabolic risk and it is the central obesity which is the main culprit for our body. ${ }^{3}$ Abdominal adiposity, is a reflection of central body fat distribution, is associated with significant metabolic abnormalities including insulin resistance, hyperinsulinemia, elevated triglycerides, glucose

1. Medical Officer, Department of Cardiology, Banghabandhu Sheikh Mujib Medical University, Dhaka, Bangladesh.

2. Assistant Professor of Medicine, Dhaka National Medical College and Hospital, Dhaka, Bangladesh.

3. Professor of Cardiology, National Institute of Cardiovascular Diseases, Dhaka, Bangladesh.

4. Associate Professor of Cardiology, National Institute of Cardiovascular Diseases, Dhaka, Bangladesh.

5. Junior Consultant, Department of Respiratory Medicine, United Hospital Limited, Dhaka, Bangladesh.

6. Specialist, Department of Neuromedicine, United Hospital Limited, Dhaka, Bangladesh.

7. Senior Consultant, Department of Medicine, Mugda Medical college and Hospital, Dhaka, Bangladesh

Address of Correspondence: Dr. Chayan Kumar Singha, Medical Officer, Banghabandhu Sheikh Mujib Medical University, Dhaka, Bangladesh. E-mail: singhachayan@yahoo.com

DOI: http://dx.doi.org/10.3329/bhj.v32i1.34168

Copyright $(2017$ Bangladesh Cardiac Society. Published by Bangladesh Cardiac Society. This is an Open Access articles published under the Creative Commons Attribution-NonCommercial 4 .0 International License (CC BY-NC). This license permits use, distribution and reproduction in any medium, provided the original work is properly cited and is not used for commercial purposes. 
intolerance, DM, as well increased incidence of hypertension (HTN), atherosclerosis and stroke ${ }^{4}, \&$ obesity is as much risk as smoking to (replace by for) developing heart disease. ${ }^{5}$ It is striking that South Asian people are more susceptible to develop central obesity than others as because their primary subcutaneous compartment is small results(resulting) in more visceral fat accumulation in response to positive energy balance, which leads to early development of metabolic syndrome and adverse cardiovascular event. ${ }^{5}$ The precise measurement of the total amount of body fat and its regional distribution is possible by using computed tomography (CT) or Magnetic resonance imaging $(\mathrm{MRI})^{6}$, but they are costly and not routinely available. Accordingly, there is a need for simple technique that can identify visceral adiposity \& there are different parameter (parameters) exist like BMI, WC, Waist/Hip ratio but none of these can accurately identify the exact impact of visceral adiposity on IHD. In this regard Amato, et al., (2010) have developed a novel sex-specific index based on WC, body mass index (BMI), triglyceride (TG), and high-density lipoprotein (HDL) cholesterol and termed it visceral adiposity index (VAI), and observed that VAI had significant correlation with visceral adiposity. And VAI showed a strong independent association with cardiovascular risk $^{7} \&$ it has an optimal cut-off pointsaccording to age. Optimal VAI cut-off points are: 2.52 (age < 30 years), 2.23 (age $\geq 30$ and $<42$ years), 1.92 (age $\geq 42$ and $<52$ years), 1.93 (age $\geq 52$ and $<66$ years) and 2.00 (age $\geq 66$ years). Patients with VAI scores greater than these cut-off points were arbitrarily defined as visceral adipose dysfunction (VAD) and this dysfunctional fat is very much deleterious for our body \& this dysfunctional fat is very much deleterious for our body. ${ }^{8}$

\section{Objective of the study:}

To find out the correlation of Visceral adiposity index score with the angiographic severity of coronary artery disease in patients with Ischemic Heart Disease.

\section{Materials and Methods:}

This was a cross sectional (not cross-sectional, but casecontrol study)analytical study, carried out in the Department of National Institute of Cardiovascular Diseases, Dhaka, Bangladesh during the period of August 2015 to July 2016. Meticulous history, detailed clinical examination and necessary investigations were done.Considering the inclusion and exclusion criteria, consecutive 100 patients of IHD who had undergone CAG were recruited and divided into two group depending on the VAD. In group I 50 patients of IHD with VAD positive \&In group II 50 patients of IHD with VAD negative. Following equation showing calculation of VAI where WC

$$
\begin{aligned}
& \text { Males: } \mathrm{VAI}=\left(\frac{\mathrm{WC}}{39.68+(1.88 \times \mathrm{BMI})}\right) \times\left(\frac{\mathrm{TG}}{1.03}\right) \times\left(\frac{1.31}{\mathrm{HDL}}\right) \\
& \text { Females: } \mathrm{VAI}=\left(\frac{\mathrm{WC}}{36.58+(1.89 \times \mathrm{BMI})}\right) \times\left(\frac{\mathrm{TG}}{0.81}\right) \times\left(\frac{1.52}{\mathrm{HDL}}\right)
\end{aligned}
$$

is expressed in $\mathrm{cm}$, BMl in $\mathrm{Kg} / \mathrm{m} 2$, $\mathrm{TG}$ in $\mathrm{mmol} / \mathrm{L}$, and $\mathrm{HDL}$ in $\mathrm{mmol} / \mathrm{L}$. After CAG the severity of coronary artery were assessed through Gensini score \& 36 points was chosen as an appropriate cut-off value and patients were divided into two groups, those with a Gensini score $\leq 36$ points were considered as absent or mild coronary artery disease and those with a Gensini score $>36$ points were considered as moderate to severe coronary artery disease (Sun and Lu, 2011).

\section{Results:}

A total of 100 patients of IHD underwent CAG were studied. In table I shows the severe form of CAD were higher in group I than group II and the difference is statistically significant. Again group II had higher no. of less severe form of CAD than group II and the difference is also statistically significant.

Table-I

Distribution of the study population according to CAD severity $(n=100)$.

\begin{tabular}{lcccccc}
\hline CAD severity (by Gensini Score) & \multicolumn{2}{c}{ Group I $(\mathrm{n}=50)$} & & \multicolumn{2}{c}{ Group II $(\mathrm{n}=50)$} & \multicolumn{1}{c}{$\mathrm{p}$ value } \\
\cline { 2 - 3 } \cline { 5 - 6 } & Number & $\%$ & & Number & $\%$ & $<0.001^{\mathrm{s}}$ \\
\hline Moderate to severe disease $(\geq 36$ points) & 39 & 78.0 & & 11 & 22.0 & $<0.001^{\mathrm{s}}$ \\
No to mild disease (<36 points) & 11 & 22.0 & & 39 & 78.0 & $<$ \\
\hline
\end{tabular}

$\mathrm{s}=$ Significant, $\mathrm{p}$ value reached from Chi Square test. $\mathrm{CAD}=$ coronary artery disease

Table-II

Mean status of VAl of the study population according to significant CAD defined by Gensini Score $(n=100)$.

\begin{tabular}{lccr}
\hline VAl & Significant CAD $(n=50)(\geq 36)$ & Insignificant CAD $(n=50)(<36)$ & $p$ value \\
\hline Mean \pm SD & $3.1 \pm 0.9$ & $2.1 \pm 0.6$ & $<0.001^{\mathrm{s}}$ \\
\hline
\end{tabular}

$\mathrm{s}=$ Significant, $\mathrm{p}$ value reached from unpaired $\mathrm{t}$ test. 


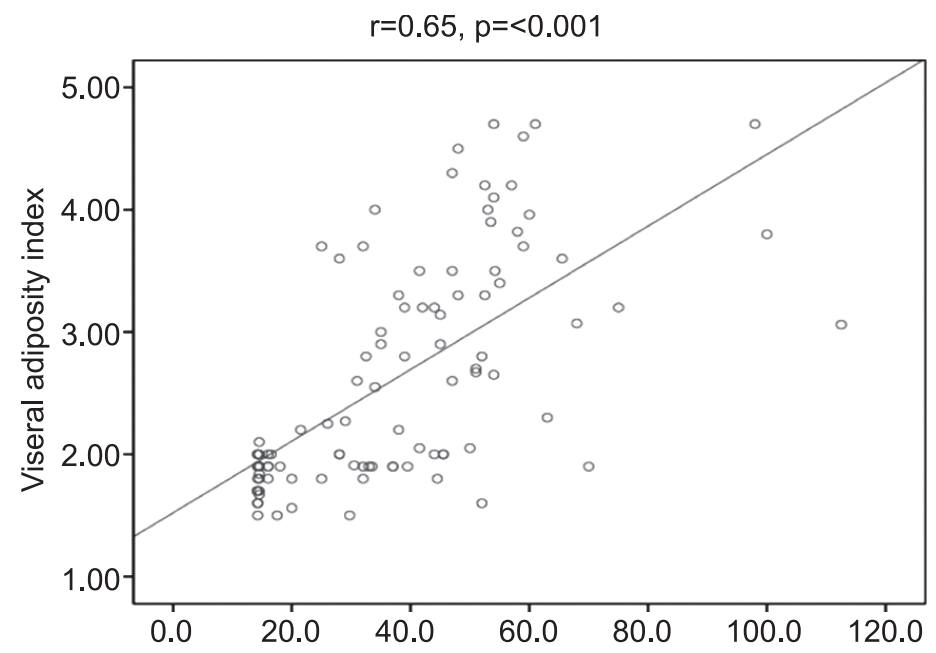

Fig.-1: Correlation between Visceral Adiposity Index and Gensini score

Table-III

\begin{tabular}{|c|c|c|c|c|}
\hline \multirow[t]{2}{*}{ Variables of interest } & \multicolumn{2}{|c|}{ Univariate } & \multicolumn{2}{|c|}{ Multivariate } \\
\hline & OR $(95 \% \mathrm{Cl})$ & $P$ value & OR $(95 \% \mathrm{Cl})$ & $P$ value \\
\hline Advance age (>50yrs) & $1.40(0.299-2.928)$ & $0.26^{\mathrm{ns}}$ & $1.22(0.119-2.101$ & $0.40^{\mathrm{ns}}$ \\
\hline Smoking & $1.27(0.180-2.119)$ & $0.22^{\text {ns }}$ & $1.10(0.112-2.001)$ & $0.31^{\mathrm{ns}}$ \\
\hline Hypertension & $1.61(1.155-3.404)$ & $0.02^{\mathrm{s}}$ & $1.52(1.120-2.691$ & $0.03^{\mathrm{s}}$ \\
\hline Dyslipidemia & $1.97(1.182-4.691)$ & $0.01^{\mathrm{s}}$ & $1.36(1.105-3.109)$ & $0.02^{\mathrm{s}}$ \\
\hline Diabetes mellitus & $2.19(1.728-6.578)$ & $0.003^{\mathrm{s}}$ & $1.97(1.596-5.241)$ & $0.005^{s}$ \\
\hline Waist Circumference (WC) & $1.94(1.121-4.112)$ & $0.001^{\mathrm{s}}$ & $1.61(1.211-3.520)$ & $0.003^{s}$ \\
\hline Increased BMI & $1.51(0.212-2.219)$ & $0.28^{\mathrm{ns}}$ & $1.44(0.121-2.106)$ & $0.32^{\mathrm{ns}}$ \\
\hline VAl & $3.89(1.611-9.320)$ & $0.003^{\mathrm{s}}$ & $3.49(1.410-8.654)$ & $0.007^{s}$ \\
\hline
\end{tabular}

OR= odds ratio, $\mathrm{Cl}=$ confidence interval

The scattered diagramme shows the significant moderate positive correlation between Gensini score \& VAI.

Table II shows the mean value of VAI in group I is more than group II and the mean difference is statistically significant.

Table III shows VAI has the highest independent prediction of causing CAD as it has the highest OR and it is statistically significant.

\section{Discussion:}

In the present study, the mean mean FBS level was $8.2 \pm 2.8 \mathrm{mmol} / \mathrm{l}$ in group I and $6.1 \pm 2.0 \mathrm{mmol} / \mathrm{l}$ in group II and the mean difference was statistically significant between the two groups $(p=0.001)$. In consistent with the present study, Han, et al. also observed the same result. The mean BMI of group I was $26.3 \pm 4.4(\mathrm{~kg} / \mathrm{m} 2)$ and that of group II was $22.5 \pm 2.3(\mathrm{~kg} / \mathrm{m} 2)$. Waist circumference was found in group I and group II $93.0 \pm 8.0$ vs $80.6 \pm 4.4$ $\mathrm{cm}$. Above two characteristics were significantly $(p=<0.001)$ higher in group I than group II \& supported by the study done by Han and colleagues ${ }^{10}$ \& Khondker
$\mathrm{R}^{11 .}$ The mean level of Visceral Adiposity Index (VAI) was observed $3.1 \pm 0.9$ and $2.1 \pm 0.6$ in significant CAD and insignificant CAD respectively. The difference of mean VAI between the significant and insignificant CAD groups were statistically significant $(p=<0.001)$ and it was compatible with the study of Han and colleagues study ${ }^{10}$. Regarding correlation coefficient of different anthropometric measurement with the severity of CAD as assessed by Gensini score, it was found that VAI $(r=0.65)$ had highest positive correlation followed by WC $(r=0.54)$ and then BMI $(0.46)$ and it was supported by the study of Han and colleagues ${ }^{10}$. Coronary artery disease (CAD) severity of the study patients were assessed by Gensini score and it was found that moderate to severe form of CAD (Gensini score e" 36 points) was $78 \%$ and $22 \%$ in group I and group II respectively. No to mild form of CAD (Gensini score <36) was found $22 \%$ and $78 \%$ in group I and group II respectively. Moderate to severe form of CAD patients were significantly more in group I than 
group II $(p=<0.001)$ and no to moderate form of CAD patients were significantly more in group II than group I $(p=<0.001)$. Study done by Han and colleagues ${ }^{10}$ also found that the mean difference of severity of CAD in relation to Gensini score between the two group was statistically significant $(p=<0.001)$. Univariate and multivariate analysis revealed that hypertension, dyslipidemia, diabetes mellitus, waist circumference and Visceral Adiposity Index were found to be the independently significant predictors of severe CAD patients with ORs being 1.61 vs. $1.52,1.97$ vs. 1.36, 2.19 vs. $1.97,1.94$ vs. 1.61 and 3.89 vs. 3.49 respectively. Thus the VAl was found to be more strong (stronger) predictor of the severity of CAD. An important study was done by Han and colleagues ${ }^{10}$ in 95 patients of CAD \& showed that VAI (OR 18.257 [95\% Cl 6.038-30.475]; P $=0.005$ ) was independently associated with Gensini score and it supports our present study.

\section{Conclusion:}

From this study it may be concluded that, Visceral Adiposity Index Score act as asimple indicator of visceral adipose mass and is significantly associated with the severity of Coronary Artery Disease in patients with Ischemic Heart Disease. So, overweight or central obesity or increased visceral adiposity, as evidenced by increased Visceral Adiposity Index Score may be considered as an emerging parameter of severe form of coronary artery disease, among the patients of Ischemic Heart Disease.

\section{Study limitations:}

Sampling method was not random rather purposive, so there was a risk of selection bias. It was conducted in a single center. Coronary angiography was assessed by visual observation, so there was every chance of inter observer variation.

\section{References:}

1. Angkurawaranon C, Jiraporncharoen W, Chenthanakij B, Doyle P, Nitsch D. Urban Environments and Obesity in Southeast Asia: A
Systematic Review, Meta-Analysis and MetaRegression. Plos One 2014;9 (11): 24-48.

2. O'Keefe J. H, Carter, M. D., Lavie, C. J. Primary and Secondary Prevention of Cardiovascular Diseases: A Practical Evidence-Based Approach. Mayo Clin Proc 2009; 84 (8): 741-57.

3. Després Jean-Pierre, Body Fat Distribution and Risk of Cardiovascular Disease.Circulation 2012; 126 (10): 1301-1313.

4. Must Aviva, McKeown, Nicola M. The Disease Burden Associated with Overweight and Obesity: Lipids Health Dis 2012;11: 94.

5. Kreatsoulas C, Anand S. S. The impact of social determinants on cardiovascular disease. Can $J$ Cardiol 2010;26 (Suppl C): 8C-13.

6. Lustgarten M, Fielding R. Assessment of analytical methods used to measure changes in body composition in the elderly and recommendations for their use in phase ii clinical trials. $J$ Nutr Health \& aging 2011;15 (5): 368-75.

7. Bozorgmanesh M, Hadaegh F, Azizi F. Predictive performance of the visceral adiposity index for a visceral adiposity-related risk: Type 2 Diabetes. Int J Endocrinol 2011;32 (4): 20-34.

8. Amato M. C, Giordano C, Pitrone M, Galluzzo A. Cutoff points of the visceral adiposity index (VAI) identifying a visceral adipose dysfunction associated with cardiometabolic risk in a Caucasian Sicilian population.Lipids Health Dis 2011;10: 183.

9. Han L, Fu KL, Jhao J et al. Visceral adiposity index score indicated the severity of coronary heart disease in Chinese adults. Diabetol Metab Syndr 2014;6(1):143.

10. Khondker R. Association of body mass index with angiographic severity of coronary artery disease in patients with acute ST- segment elevation myocardial infarction MD (Cardiology) Thesis, Dhaka: National Institute of Cardiovascular Disease (NICVD), 2015. 